\title{
Analisis Ergonomi Makro Dengan Pendekatan SHIP Terhadap Media Ajar Matematika Di MIN 3 Jember
}

\author{
Mohammad Kholil \\ IAIN Jember \\ Surel: muad.kholil@gmail.com
}

\begin{abstract}
Abstrak
Matematika merupakan salah satu cabang ilmu yang menerapkan logika dalam proses berfikirnya. Untuk itu perlu menggunakan bantuan media ajar yang baik dalam menyampaikan materi matematika kepada siswa agar lebih mudah untuk dipahami dan dimengerti siswa. Menganalisa media ajar bukan merupakan proses yang mudah, diperlukan upaya untuk menganalisa efektifitas dan validitasnya. Hal tersebut dapat dilakukan melalui analisis ergonomi dengan pendekatan SHIP. Tujuan penelitian ini adalah 1) untuk mendeskripsikan media ajar matematika melalui analisis ergonomi makro dengan pendekatan SHIP dan 2) pengaruhnya terhadap hasil belajar siswa di MIN 3 Jember. Metode penelitian ini menggunakan pendekatan kuantitatif dengan jenis penelitian expost facto. Penentuan sampelnya menggunakan cluster random sampling. Teknik pengumpulan data dalam penelitian ini adalah angket, wawancara, dan dokumentasi dan dianalisis menggunakan regresi linier sederhana. Media ajar matematika berdasarkan ergonomi makro dengan pendekatan SHIP dianalisis berdasarkan hasil angket yang telah diisi oleh siswa. Data angket yang terkumpul dianalisis berdasarkan Skala Likert dan dikonversikan ke kriteria penskoran. Berdasarkan hasil analisis data dengan regresi linier sederhana, diperoleh hasil bahwa persamaan regresi linier $Y=68,288+0,060 \mathrm{X}$. Regresi ini termasuk regresi yang tak berarti. Media ajar yang dianalisis secara ergonomi makro berpengaruh terhadap hasil belajar siswa di MIN 3 Jember meskipun pengaruhnya tidak signifikan.
\end{abstract}

Kata Kunci: Analisis ergonomi makro, Pendekatan SHIP, Media ajar matematika

\section{Abstract}

Mathematics is one branch of science that applies logic in the process of thinking. For this reason, it is necessary to use the help of good teaching media in delivering mathematical material to students to make it easier for students to understand. Analyzing instructional media is not an easy process, an effort is needed to analyze its effectiveness and validity. This can be done through ergonomics analysis with the SHIP approach. The purpose of this study is 1) to describe the mathematics teaching media through macro ergonomics analysis with the 
SHIP approach and 2) its effect on student learning outcomes in MIN 3 Jember. This research method uses a quantitative approach to the type of ex post facto research. Determination of the sample using cluster random sampling. Data collection techniques in this study were questionnaires, interviews, and documentation and were analyzed using simple linear regression. Mathematical teaching media based on macro ergonomics with the SHIP approach are analyzed based on the results of the questionnaire that has been filled out by students. The questionnaire data collected was analyzed based on a Likert Scale and converted to scoring criteria. Based on the results of data analysis with simple linear regression, the results obtained that the linear regression equation $Y=68.288+0.060 X$. This regression is meaningless. Teaching media analyzed in macro ergonomics affect student learning outcomes in MIN 3 Jember although the effect is not significant.

Keywords : analysis of macro ergonomics, SHIP approach, mathematics teaching media

\section{A. PENDAHULUAN}

Keberadaan MGMP merupakan pemenuhan kebutuhan guru mata pelajaran, yang selalu dituntut untuk mampu melakukan pengembangan pembelajaran. Salah satu hasil kerja MGMP berupa media ajar yang diperlukan untuk menyampaikan materi, ide atau gagasan dalam proses pembelajaran.

Sistem kerja MGMP memiliki banyak aspek ergonomi yang terlibat dalam proses organisasi seperti interaksi antara guru dengan sesama guru, mata pelajaran, alat/media, kondisi lingkungan internal dan eksternal, juga organisasi lain yang terkait. Interaksi yang terjadi dapat mempengaruhi pola dan kualitas hasil, yang salah satunya berupa media ajar.

Media ajar adalah alat bantu yang berfungsi sebagai penunjang dalam pembelajaran yang secara sengaja dan terencana disiapkan atau disediakan guru untuk mempresentasikan dan menjelaskan bahan pelajaran, serta digunakan siswa untuk dapat terlibat langsung dengan pembelajaran. ${ }^{1}$ Media ajar yang tersistem baik, dapat mewakili penyampaian materi yang bersifat holistik (menyeluruh), interdisipliner, dan dapat melibatkan guru dan siswa secara aktif, sangat penting diterapkan dalam proses musyawarah kerja untuk menciptakan output yang efisien, efektif, dan produktif. Media ajar, baik secara langsung maupun tidak, dapat mempengaruhi kinerja, sikap kerja, situasi kerja, dan kerjasama antara manajemen organisasi dan guru anggota, serta lebih jauh lagi, kerjasama antara guru dan siswa.

Adanya keberagaman latar belakang, kepribadian, kepercayaan, kemampuan, pendidikan dan pengalaman dapat mempengaruhi media ajar yang dihasilkan. Melihat begitu besar pengaruhnya bagi kesuksesan pencapaian mutu yang diinginkan, maka penting bagi sebuah organisasi pendidikan untuk menganalisa media ajar yang dihasilkan.

Berikutnya, Ergonomi makro merupakan suatu pendekatan sosioteknikal mulai tingkatan paling atas sampai tingkat paling bawah yang diterapkan pada perancangaan

\footnotetext{
${ }^{1}$ Gatot Muhsetyo and dkk., Pembelajaran Matematika SD (Tangerang Selatan: Universitas Terbuka, 2013).
} 
sistem kerja secara keseluruhan untuk mengoptimalkan desain sistem kerja dan memastikan agar sistem kerja tersebut dapat berjalan secara harmonis. ${ }^{2}$ Dilakukannya pendekatan ergonomi makro akan membentuk sistem kerja yang harmonis untuk meningkatkan komitmen pekerja, kesehatan dan keamanan, produktivitas, dan kepuasan kerja. ${ }^{3}$

Berhubungan dengan analisa ergonomi ini, telah dilakukan penelitian sebelumnya oleh Hari Purnomo dan Kesuma herdianto. ${ }^{4}$ Tujuan dalam penelitian mereka adalah untuk mengetahui pengaruh setiap komponen sistem kerja terhadap tingkat produktivitas. Komponen sistem kerja yang dianalisis adalah faktor organisasi, regulasi, budaya, personality, pekerjaan, lingkungan kerja, peralatan kerja serta manajemen kerja. Penyelesaian masalah menggunakan pendekatan Ergonomi Makro dan Analisis Jalur (Path Analysis). Ergonomi makro, digunakan untuk mendesain komponen sistem kerja yang akan digunakan dalam menyusun kuesioner. Sedangkan analisis jalur digunakan untuk menganalisis pola hubungan antar variabel dan untuk mengetahui pengaruh langsung maupun tidak langsung dari komponen sistem kerjaterhadap produktivitas kerja.

Sedangkan penelitian tentang ergonomi lainnya yang dilakukan dalam pembelajaran di kelas adalah Pengaruh Pembelajaran Dengan Pendekatan Ergonomi Partisipatori

\footnotetext{
${ }^{2}$ H.W.Hendrick and B.M.Kleiner, Macroergonomics Theory, Methods, and Applications (New Jersey - London: Lawrence Erlbaum Associates, 2012).

${ }^{3}$ Hari Purnomo and Kesuma Ferdianto, "Desain Sistem Kerja Pada Pengrajin Mendong Dengan Pendekatan Ergonomi Makro," Prosiding Seminar Nasional Sains Dan Teknologi Ke-2 Tahun 2011 Fakultas Teknik Universitas Wahid Hasyim Semarang, 2011, 12-17.

${ }^{4}$ Purnomo and Ferdianto.
}

(PEP) Berbasis Asesmen Portofolio Terhadap Kelelahan Dan Hasil Belajar IPA (Biologi) Siswa Kelas X SMA Tahun Pelajaran 2011/2012. ${ }^{5}$ Hasil penelitian ini adalah mengetahui tingkat kelelahan dan hasil belajar siswa melalui serangkaian pembelajaran dengan pendekatan ergonomi partisipatori.

Dalam penelitian ini, analisa ergonomi makro terhadap media ajar dilakukan dengan pendekatan sistematik, holistik, interdisipliner, dan partisipator atau disingkat dengan istilah SHIP. ${ }^{6}$ Pendekatan ini mencakup semua permasalahan dalam sistem kerja yang harus dipecahkan melalui pendekatan sistem, dikaji secara menyeluruh dan terus menerus atau holistik dan melalui berbagai disiplin ilmu serta menggunakan pendekatan partisipator dengan maksud agar semua komponen dalam suatu sistem dapat terlibat dari tahap perencanaan, pelaksanaan, dan evaluasi sehingga akan diketahui hasilnya. $^{7}$

Matematika merupakan salah satu cabang ilmu yang menerapkan logika dalam proses berfikirnya. ${ }^{8}$ Sebagai suatu ilmu yang bersifat simbolis, matematika tidak akan bermanfaat tanpa logika berfikir yang benar. Logika yang diasah dengan baik dalam ilmu matematika merupakan cara

\footnotetext{
${ }^{5}$ H. Nugroho, "Pengaruh Pembelajaran Dengan Pendekatan Ergonomi Partisipatori (Pep) Berbasis Asesmen Portofolio Terhadap Kelelahan Dan Hasil Belajar Ipa (Biologi) Siswa Kelas X Sma Tahun Pelajaran 2011/2012," Jurnal Bakti Saraswati 3, no. 02 (2014): 5369.

${ }^{6}$ Marcelo M. Soares and Francisco Rebelo, Ergonomics In Design: Methods \& Techniques (London \& New York: CRC Press, 2017).

${ }^{7}$ Soares and Rebelo.

${ }^{8}$ Mohammad Kholil, "Implementasi Pembelajaran Inquiry Untuk Meningkatkan Kemampuan Berpikir Logis Pada Pokok Bahasan Logika Matematika," LAPLACE: Jurnal Pendidikan Matematika 1, no. 1 (2018): 15-25.
} 
untuk menguasai ilmu lainnya. ${ }^{9}$ Logika menawarkan penalaran logis dalam menguji suatu fenomena / persoalan. Untuk itu perlu menggunakan bantuan media ajar yang baik dalam menyampaikan materi matematika kepada siswa agar lebih mudah untuk dipahami dan dimengerti siswa. ${ }^{10}$ Oleh karena itu, penelitian ini dilakukan pada pembelajaran matematika yang telah diterapkan oleh guru dalam menggunakan media ajar matematika di MIN 3 Jember dengan mengguakan analisa ergonomi makro dengan pendekatan SHIP. Sedangkan tujuan penelitian ini adalah 1) untuk mendeskripsikan media ajar matematika dalam analisis ergonomi makro dengan pendekatan SHIP; dan 2) pengaruhnya terhadap hasil belajar siswa di Madrasah Ibtidaiyah Negeri 3 Jember.

\section{B. METODE PENELITIAN}

Metode penelitian ini menggunakan pendekatan kuantitatif. Karena data yang diperoleh berupa angka-angka yang nantinya akan dianalisis secara kuantitatif atau statistik. ${ }^{11}$ Jenis penelitian dalam penelitian ini termasuk jenis penelitian expost facto. Hal ini karena dalam penelitian ini tidak memberikan perlakuan kepada responden melainkan hanya mengungkapkan fakta pada diri responden. ${ }^{12}$

\footnotetext{
${ }^{9}$ M. Kholil, "Students' Creative Thinking Skills in Solving Mathematical Logic Problem with Open-Ended Approaches," in Journal of Physics: Conference Series, vol. 1465, 2020, https://doi.org/10.1088/17426596/1465/1/012044.

${ }^{10}$ Muhsetyo and Dkk., Pembelajaran Matematika SD.

${ }^{11}$ Sugiyono, Metode Penelitian Pendidikan (Pendekatan Kuantitatif, Kualitatif Dan R\&D) (Bandung: Penerbit CV. Alfabeta, 2017).

12 John W. Creswell and J. David Creswell, Research Design: Qualitative, Quantitative, and Mixed Methods
}

Dalam penelitian ini, populasi yang ditetapkan oleh peneliti yaitu seluruh siswa kelas atas MIN 3 Jember tahun pelajaran 2019/2020 yang berjumlah 224 siswa yang terdiri dari 81 siswa kelas 4, 71 siswa kelas 5 dan 72 siswa kelas 6. Teknik penentuan sampel dalam penelitian ini menggunakan teknik probability sampling. Hal ini karena teknik probability sampling memberikan peluang yang sama bagi setiap anggota populasi untuk dipilih menjadi sampel. ${ }^{13}$

Jenis penentuan sampelnya menggunakan cluster random sampling dengan cara mengambil sampel dari anggota populasi secara berkelompok (kelas) tanpa memperhatikan strata atau tingkatan yang ada dalam populasi tersebut atau populasi dianggap homogen. ${ }^{14}$ Sedangkan jumlah sampel yang diambil sebesar 25\% dari jumlah populasi yaitu 56 siswa. ${ }^{15}$ Namun peneliti mengambil jumlah sampel sebanyak 60 siswa untuk memudahkan penelitian dan agar hasilnya lebih baik.

Teknik pengumpulan data dalam penelitian ini adalah angket, wawancara, dan dokumentasi. Wawancara digunakan sebagai teknik pengumpulan data apabila peneliti ingin melakukan studi pendahuluan untuk menemukan permasalahan yang harus diteliti, dan juga apabila peneliti ingin mengetahui hal-hal yang lebih mendalam dalam penelitian. ${ }^{16}$ Wawancara dalam

\footnotetext{
Approaches, Fitth Edit (United States of America: SAGE Publications, Inc, 2018).

${ }^{13}$ Sugiyono, Metode Penelitian Pendidikan (Pendekatan Kuantitatif, Kualitatif Dan R\&D).

${ }^{14}$ Zainal Arifin, Penelitian Pendidikan Metode Dan Paradigma Baru (Bandung: PT. Remaja Rosdakarya, 2012).

${ }^{15}$ Suharsimi Arikunto, Prosedur Penelitian: Suatu Pendekatan Praktik (Jakarta: Rineka Cipta, 2013).

${ }^{16}$ Sugiyono, Metode Penelitian Pendidikan (Pendekatan Kuantitatif, Kualitatif Dan R\&D).
} 
penelitian ini digunakan untuk mencari informasi lebih dalam tentang pembuatan media ajar matematika dalam analisis ergonomi makro dengan pendekatan SHIP. Narasumber dalam penelitian ini adalah guru mata pelajaran matematika di Madrasah Ibtidaiyah Negeri 3 Jember.

Selanjutnya data dikumpulkan melalui instrumen berupa angket. Angket merupakan teknik pengumpulan data yang dilakukan dengan cara memberi seperangkat pertanyaan atau pernyataan tertulis kepada responden untuk dijawabnya. ${ }^{17}$ Angket dapat berupa pertanyaan/pernyataan tertutup atau terbuka. ${ }^{18}$ Adapun angket atau kuesioner dalam penelitian ini berupa pernyataanpernyataan tertutup yang terdiri dari 32 pernyataan dengan 5 pilihan jawaban yang bertujuan untuk mendapatkan informasi mengenai media ajar matematika yang dibuat berdasarkan analisis ergonomi makro dengan pendekatan SHIP. Bentuk skala yang digunakan adalah skala pengukuran model Likert. Skala angket ini terdiri dari pernyataan yang favourable (pernyataan positif) dan unfavourable (pernyataan negatif) yang tujuannya untuk melihat konsistensi subjek memberikan jawaban. Berikut adalah pedoman penskoran angket. ${ }^{19}$

Tabel 1. Ketentuan Penskoran Angket

\begin{tabular}{|l|c|c|}
\hline \multicolumn{1}{|c|}{ Keterangan } & Favourable $(+)$ & Unfavourable (-) \\
\hline Sangat Sesuai & 5 & 1 \\
\hline Sesuai & 4 & 2 \\
\hline Kurang Sesuai & 3 & 3 \\
\hline Tidak Sesuai & 2 & 4 \\
\hline
\end{tabular}

${ }^{17}$ Creswell and Creswell, Research Design: Qualitative, Quantitative, and Mixed Methods Approaches.

${ }^{18}$ Sugiyono, Metode Penelitian Pendidikan (Pendekatan Kuantitatif, Kualitatif Dan R\&D).

${ }^{19}$ Daniel Stockemer, Quantitative Methods for the Social Sciences: A Practical Introduction with Examples in SPSS and Stata (Switzerland: Springer International Publishing, 2019), https://doi.org/10.1007/978-3-319-99118-4.

\begin{tabular}{|l|c|c|}
\hline Sangat Tidak Sesuai & 1 & 5 \\
\hline Skor Maksimal & 16 item $\times 5=80$ & 16 item $\times 5=80$ \\
\hline Jumlah Skor & \multicolumn{2}{|c|}{160} \\
\hline \multicolumn{1}{|c|}{ Sedangkan data dokumentasi dalam }
\end{tabular}

penelitian ini berupa gambaran umum lokasi penelitian, data siswa, data media ajar matematika, serta data mengenai hasil belajar ulangan harian dan nilai PTS ganjil di MIN 3 Jember.

Untuk menghasilkan data yang akan digunakan dalam analisis data maka data tersebut harus memenuhi standar validitas dan reliabilitas instrumen. Uji validitas dalam penelitian ini menggunakan validitas eksternal, yaitu instrumen angket yang telah dibuat diuji cobakan kepada siswa-siswa non sampel. ${ }^{20}$ Kemudian data yang diperoleh diolah menggunakan bantuan aplikasi SPSS statistics. Valid tidaknya data dapat ditentukan dengan membandingkan hasil $r$ pada output SPSS Statistics dengan $r$ tabel dengan taraf signifikasi $\alpha=5 \%$ dan derajat kebebasan $\mathrm{db}=\mathrm{N}-\mathrm{nr}$ dimana $\mathrm{N}$ adalah jumlah sampel dan $\mathrm{nr}$ adalah banyaknya variabel. Jika $r_{\text {hitung }}>r_{\text {tabel, maka data }}$ dinyatakan valid. Sebaliknya jika $\mathrm{r}_{\text {hitung }}<\mathrm{rtabel}_{\text {, }}$ maka data tidak valid. ${ }^{21}$ Selanjutnya uji reliabilitas dalam penelitian ini juga menggunakan bantuan SPSS statistics dengan cara melihat nilai alpha cronbach dari hasil outputnya. Instrumen angket dalam penelitian dikatakan reliabel jika koefisien reliabilitas $r_{11}>0,6.22$

Adapun variabel penelitian dalam penelitian ini terdiri dari analisis ergonomi

\footnotetext{
${ }^{20}$ Stockemer.

${ }^{21}$ Abdulkader Aljandali, Quantitative Analysis and IBM SPSS Statistics : A Guide for Business and Finance (Switzerland: Springer International Publishing, 2016), https://doi.org/10.1007/978-3-319-45528-0.

22 Particia Leavy, Research Design: Quantitative, Qualitative, Mixed Methods, Arts-Based, and CommunityBased Participatory Research Approaches (New York: The Guilford Press, 2017).
} 
makro terhadap media ajar matematika sebagai variabel bebas $(\mathrm{X})$ dan rata-rata hasil belajar ulangan harian siswa dan nilai PTS ganjil di MIN 3 Jember sebagai variabel terikat (Y). Sedangkan Hipotesis dalam penelitian ini terdiri dari hipotesis nihil $\left(\mathrm{H}_{0}\right)$, yaitu tidak ada pengaruh media ajar dalam analisis ergonomi makro dengan pendekatan SHIP terhadap hasil belajar siswa di MIN 3 Jember, dan hipotesis alternatif $\left(\mathrm{H}_{\mathrm{a}}\right)$, yaitu terdapat pengaruh media ajar dalam analisis ergonomi makro dengan pendekatan SHIP terhadap hasil belajar siswa di MIN 3 Jember.

Setelah memperoleh data, analisis data dalam penelitian ini dilakukan dengan dua cara, yaitu analisis deskriptif dan analisis inferensial. Analisis deskriptif dilakukan untuk menganalisis data dengan cara mendeskripsikan atau menggambarkan data yang telah terkumpul berdasarkan keadaan data setiap variabel. Sedangkan analisis inferensial dilakukan untuk menguji hipotesis yang telah dibuat sebelumnya.

Analisis deskriptif dilakukan terhadap variabel bebas dan variabel terikat. Data ergonomi makro terhadap media ajar matematika dan hasil belajar dikategorisasikan berdasarkan lima kategori, yaitu sangat tinggi, tinggi, sedang, rendah, dan sangat rendah. Pengkategorian ditentukan dengan menggunakan rumus nilai rata-rata ideal $(\mu)$ dan nilai standar deviasi ideal $\left(\mathrm{SD}_{\mathrm{i}}\right)$ sebagai berikut:

$$
\begin{aligned}
\mu & =\frac{1}{2}(\text { skor maks }+ \text { skor min }) \\
\mathrm{SD}_{\mathrm{i}} & =\frac{1}{6}(\text { skor maks }- \text { skor min }) .{ }^{23}
\end{aligned}
$$

Dari hasil perhitungan rumus tersebut disesuaikan dengan jenis kategori seperti pada tabel berikut: ${ }^{24}$

\footnotetext{
${ }^{23}$ Saifuddin Azwar, Penyusunan Skala Psikologi (Jogjakarta: Pustaka Pelajar, 2018).

${ }^{24}$ Azwar.
}

Tabel 2. Pedoman Kategorisasi Skor

\begin{tabular}{|c|l|}
\hline Interval Skor & \multicolumn{1}{|c|}{ Kategori } \\
\hline$X>\mu+1,5$ SDi & Sangat Tinggi \\
\hline$\mu+0,5$ SDi $<X \leq \mu+1,5$ SDi & Tinggi \\
\hline$\mu-0,5$ SDi $<X \leq \mu+0,5$ SDi & Sedang \\
\hline$\mu-1,5$ SDi $<X \leq \mu-0,5$ SDi & Rendah \\
\hline$X \leq \mu-1,5$ SDi & Sangat Rendah \\
\hline
\end{tabular}

Analisis inferensial dilakukan untuk menguji hipotesis yang telah dibuat sebelumnya. Uji hipotesis dalam penelitian ini menggunakan uji analisis regresi linier sederhana yang diawali dengan uji prasyarat meliputi uji normalitas, uji linieritas, dan uji heteroskedastisitas. ${ }^{25}$ Analisis regresi linier sederhana terdiri dari satu variabel bebas dan satu variabel terikat, dengan persamaan:

$$
\mathrm{Y}=a+b \mathrm{X}
$$

Dimana $\mathrm{Y}$ adalah variabel terikat, $\mathrm{X}$ variabel bebas, a konstanta regresi, dan $\mathrm{b}$ koefisien regresi. ${ }^{26}$ Dalam penelitian ini, regresi linier sederhana akan dihitung dengan menggunakan bantuan SPSS Statistics.

Untuk pengambilan keputusan pada uji regresi linier sederhana berdasarkan pada dua hal, yaitu dengan membandingkan antara thitung dengan tabel. Jika nilai thitung > tabel, maka $\mathrm{H}_{0}$ ditolak dan $\mathrm{H}_{\mathrm{a}}$ diterima yang artinya terdapat pengaruh variabel bebas terhadap variabel terikat. Jika nilai thitung < ttabel, maka $\mathrm{H}_{0}$ diterima dan $\mathrm{H}_{\mathrm{a}}$ ditolak yang artinya tidak ada pengaruh variabel bebas terhadap variabel terikat. ${ }^{27}$

\section{HASIL DAN PEMBAHASAN}

\footnotetext{
${ }^{25}$ Christian Heumann and Michael Schomaker Shalabh, Introduction to Statistics and Data Analysis: With Exercises, Solutions and Applications in R, Technometrics (Switzerland: Springer International Publishing, 2016), https://doi.org/10.1007/978-3-319-46162-5. ${ }^{26}$ William E Wagner, Using IBM SPSS Statistics for Research Methods and Social Science Statistics, fifth Edit (United States of America: SAGE Publications, Inc, 2015). 27 Wagner.
} 
Sebelum melakukan analisis data deskriptif maupun uji hipotesis, terlebih dahulu dilakukan uji validitas dan reliabilitas terhadap data yang telah diperoleh. Untuk menentukan valid tidaknya data dapat dilihat dengan menggunakan nilai rhitung pada output SPSS Statistics dan dibandingkan dengan nilai

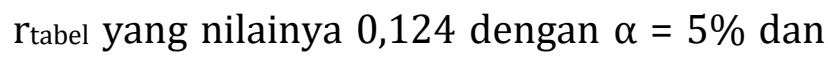
$\mathrm{db}=58$. Hasil validitas data dapat dilihat pada tabel 3 berikut.

Tabel 3. Hasil Validitas Angket

\begin{tabular}{|c|c|c|c|c|c|}
\hline $\begin{array}{c}\text { No. } \\
\text { Item }\end{array}$ & rhitung & Ket. & $\begin{array}{c}\text { No. } \\
\text { Item }\end{array}$ & rhitung & Ket. \\
\hline 1 & 0,514 & Valid & 17 & 0,544 & Valid \\
\hline 2 & 0,355 & Valid & 18 & 0,541 & Valid \\
\hline 3 & 0,562 & Valid & 19 & 0,484 & Valid \\
\hline 4 & 0,557 & Valid & 20 & 0,474 & Valid \\
\hline 5 & 0,590 & Valid & 21 & 0,652 & Valid \\
\hline 6 & 0,493 & Valid & 22 & 0,438 & Valid \\
\hline 7 & 0,423 & Valid & 23 & 0,597 & Valid \\
\hline 8 & 0,478 & Valid & 24 & 0,441 & Valid \\
\hline 9 & 0,547 & Valid & 25 & 0,608 & Valid \\
\hline 10 & 0,493 & Valid & 26 & 0,642 & Valid \\
\hline 11 & 0,339 & Valid & 27 & 0,411 & Valid \\
\hline 12 & 0,639 & Valid & 28 & 0,514 & Valid \\
\hline 13 & 0,400 & Valid & 29 & 0,651 & Valid \\
\hline 14 & 0,468 & Valid & 30 & 0,479 & Valid \\
\hline 15 & 0,490 & Valid & 31 & 0,614 & Valid \\
\hline 16 & 0,428 & Valid & 32 & 0,594 & Valid \\
\hline
\end{tabular}

Dari tabel 3 tersebut dapat dilihat bahwa hasil validitas semua item adalah valid. Ini artinya bahwa instrumen yang telah dibuat dapat digunakan dalam penelitian. Selanjutnya akan dianalisis reliabilitas data yang telah diperoleh. Dalam penelitian ini reliabilitas dilakukan dengan cara melihat nilai alpha cronbach dari hasil output SPSS berikut.

Tabel 4. Output Reliabilitas

\begin{tabular}{|r|r|}
\hline $\begin{array}{c}\text { Cronbach's } \\
\text { Alpha }\end{array}$ & N of Items \\
\hline, 909 & 32 \\
\hline
\end{tabular}

Dari tabel 4 di atas dapat dilihat bahwa koefisien reabilitas $\mathrm{r} 11=0,909>0,60$. Hal ini menunjukkan bahwa instrumen penelitian yang telah dibuat reliabel atau konsisten.
Oleh karena itu, angket dapat digunakan untuk pengambilan data terhadap sampel yang telah ditentukan.

Berikutnya adalah analisis data deskriptif dan analisis inferensial. Analisis data deskriptif terdiri dari analisis deskriprif terhadap skor hasil pengisian angket media ajar matematika berdasarkan analisis ergonomi makro dengan pendekatan SHIP dan skor hasil belajar matematika siswa. Sedangkan analisis inferensial dilakukan untuk menguji hipotesis yang telah dibuat sebelumnya.

\section{Analisis Deskriprif Skor Hasil Pengisian Angket Media Ajar Matematika Berdasarkan Analisis Ergonomi Makro Dengan Pendekatan SHIP}

Dari skor hasil pengisian angket yang dilakukan oleh sampel pada penelitian ini, diperoleh skor maskimal adalah 160 dan skor minimal adalah 32. Selanjutnya skor maksimal dan minimal tersebut disubstitusikan ke persamaan (1) dan (2) sehingga diperoleh $\mu=96$ dan $\mathrm{SD}_{\mathrm{i}}=21$. Hasil ini kemudian disubstitusikan ke tabel 2 untuk memperoleh pedoman kategorisasi skor seperti pada tabel 5 berikut.

Tabel 5. Pedoman Kategorisasi Skor

\begin{tabular}{|c|c|}
\hline Interval Skor & Kategori \\
\hline $\mathrm{X}>128$ & Sangat Tinggi \\
\hline $107<\mathrm{X} \leq 128$ & Tinggi \\
\hline $85<\mathrm{X} \leq 107$ & Sedang \\
\hline $64<\mathrm{X} \leq 85$ & Rendah \\
\hline $\mathrm{X} \leq 64$ & Sangat Rendah \\
\hline
\end{tabular}

Dengan tabel 5 di atas, dapat dibentuk kategorisasi media ajar matematika berdasarkan analasis ergonomi makro dengan pendekatan SHIP sebagai berikut.

Tabel 6. Kategorisasi Media Ajar Matematika

\begin{tabular}{|l|l|l|}
\hline Interval Skor & Kategori & Jumlah \\
\hline
\end{tabular}




\begin{tabular}{|c|c|c|}
\hline$X>128$ & Sangat Tinggi & 1 \\
\hline $107<X \leq 128$ & Tinggi & 22 \\
\hline $85<X \leq 107$ & Sedang & 30 \\
\hline $64<X \leq 85$ & Rendah & 7 \\
\hline$X \leq 64$ & Sangat Rendah & 0 \\
\hline \multicolumn{2}{|c|}{ Jumlah } & 60 \\
\hline
\end{tabular}

Berdasarkan tabel 6 di atas, diketahui bahwa 1 siswa berpendapat bahwa media ajar matematika yang telah digunakan oleh guru dalam pembelajaran berada dalam kategori sangat tinggi, 22 siswa berpendapat bahwa media ajar matematika yang telah digunakan oleh guru dalam pembelajaran berada dalam kategori tinggi, 30 siswa berpendapat bahwa media ajar matematika yang telah digunakan oleh guru dalam pembelajaran berada dalam kategori sedang, dan 7 siswa berpendapat bahwa media ajar matematika yang telah digunakan oleh guru dalam pembelajaran berada dalam kategori rendah. Dari paparan tersebut, dapat disimpulkan bahwa media ajar yang digunakan guru memiliki kategori yang bervariasi dalam hal keergonomisannya. $1,67 \%$ responden menyatakan bahwa media ajar matematika yang dianalisis dengan ergonomi makro berada pada kategori sangat tinggi. $36,67 \%$ responden menyatakan bahwa media ajar matematika yang dianalisis dengan ergonomi makro berada pada kategori tinggi, 50\% responden siswa menyatakan bahwa media ajar matematika yang dianalisis dengan ergonomi makro berada pada kategori sedang. dan 11,66\% responden menyatakan bahwa media ajar matematika yang dianalisis dengan ergonomi makro berada pada kategori rendah.

Hasil ini menunjukkan bahwa rata-rata siswa menyatakan media ajar matematika yang gunakan oleh guru dalam pembelajaran di kelas termasuk ergonomis. Dari hasil observasi yang dilakukan diperoleh bahwa guru matematika di MIN 3 Jember membuat persiapan yang baik dalam penggunaan media ajar ajar matematika di kelas sehingga materi tersampaikan dengan baik kepada siswa. Hal ini sesuai dengan pendapat Muhsetyo bahwa media ajar yang tersistem baik, dapat mewakili penyampaian materi yang bersifat holistik (menyeluruh), interdisipliner, dan dapat melibatkan guru dan siswa secara aktif sehingga lebih mudah untuk dipahami dan dimengerti siswa. ${ }^{28}$

\section{Analisis Deskriprif Skor Hasil Belajar Matematika Siswa}

Skor maksimal hasil belajar siswa adalah 100. Sedangkan skor minimalnya adalah 0 . Selanjutnya skor maksimal dan skor minimal tersebut disubstitusikan ke persamaan (1) dan (2) sehingga diperoleh $\mu=50$ dan $S_{i}=$ 17. Hasil ini kemudian disubstitusikan ke tabel 2 untuk memperoleh pedoman kategorisasi skor seperti pada tabel 7 berikut.

Tabel 7. Pedoman Kategorisasi Skor

\begin{tabular}{|c|c|}
\hline Interval Skor & Kategori \\
\hline $\mathrm{X}>76$ & Sangat Tinggi \\
\hline $59<\mathrm{X} \leq 76$ & Tinggi \\
\hline $42<\mathrm{X} \leq 59$ & Sedang \\
\hline $25<\mathrm{X} \leq 42$ & Rendah \\
\hline $\mathrm{X} \leq 25$ & Sangat Rendah \\
\hline
\end{tabular}

Dengan tabel 7 di atas, dapat dibentuk kategorisasi Hasil belajar matematika siswa MIN 3 Jember sebagai berikut.

Tabel 8. Kategorisasi Hasil Belajar

\begin{tabular}{|c|c|c|}
\hline Interval Skor & Kategori & Jumlah \\
\hline $\mathrm{X}>76$ & Sangat Tinggi & 20 \\
\hline $59<\mathrm{X} \leq 76$ & Tinggi & 40 \\
\hline $42<\mathrm{X} \leq 59$ & Sedang & 0 \\
\hline $25<\mathrm{X} \leq 42$ & Rendah & 0 \\
\hline
\end{tabular}

${ }^{28}$ Muhsetyo and Dkk., Pembelajaran Matematika SD. 


\begin{tabular}{|c|c|c|}
\hline $\mathrm{X} \leq 25$ & Sangat Rendah & 0 \\
\hline \multicolumn{2}{|c|}{ Jumlah } & 60 \\
\hline
\end{tabular}

Berdasarkan tabel 8 di atas, diketahui bahwa hasil belajar matematika siswa yang berada dalam kategori sangat tinggi sebanyak 20 orang atau 33,33\%, dan hasil belajar matematika siswa yang berada dalam kategori tinggi sebanyak 40 siswa atau 66,67\%. Dari hasil ini, dapat disimpulkan bahwa hasil belajar siswa rata-rata berada pada kategori tinggi.

Hal ini selaras dengan hasil analisis deskriptif media ajar matematika. Rata-rata siswa berpendapat bahwa media ajar yang digunakan guru dalam pembelajaran di kelas termasuk kategori ergonomis sehingga berimplikasi terhadap hasil belajar siswa yang berada pada kategori tinggi.

\section{Uji Prasyarat Regresi}

Sebelum melakukan uji hipotesis terlebih dahulu dilakukan uji prasyarat regresi yaitu uji normalitas, uji linieritas, uji heteroskedastisitas. Uji normalitas dalam penelitian ini menggunakan uji normalitas kolmogorov smirnov yang dilakukan dengan bantuan IBM SPSS Statistics dimana hasil outputnya seperti pada tabel 9 berikut.

Tabel 9. Output SPSS Uji Normalitas

\begin{tabular}{|l|r|r|r|r|r|r|}
\hline \multicolumn{1}{|c|}{ Tests of Normality } \\
& \multicolumn{3}{|c|}{$\begin{array}{c}\text { Kolmogorov- } \\
\text { Smirnov }\end{array}$} & \multicolumn{4}{c|}{ Shapiro-Wilk } \\
\cline { 2 - 8 } & Statistic & df & Sig. & Statistic & df & Sig. \\
\hline $\begin{array}{l}\text { Ergonomi Media Ajar } \\
\text { Matematika }\end{array}$ &, 088 & 60 &, $200^{*}$ &, 970 & 60 &, 147 \\
Hasil Belajar &, 109 & 60 &, 074 &, 966 & 60 &, 093 \\
\hline
\end{tabular}

*. This is a lower bound of the true significance.

a. Lilliefors Significance Correction

Berdasarkan tabel 9 di atas diperoleh nilai signifikansi dari data ergonomi media ajar matematika adalah 0,200 dan nilai signifikansi dari data hasil belajar sebesar 0,074. Hal ini berarti nilai signifikasi ergonomi media ajar matematika 0,200 > 0,05 dan nilai signifikansi hasil belajar 0,074 $>0,05$. Sesuai dengan dasar pengambilan keputusan dalam uji normalitas kolmogorov smirnov dapat disimpulkan bahwa data ergonomi media ajar matematika dan data hasil belajar berdistribusi normal.

Berikutnya uji linieritas dalam penelitian ini menggunakan bantuan IBM SPSS Statistics dengan hasil output uji linieritas sebagai berikut.

Tabel 10. Output SPSS Uji Linieritas ANOVA Table

\begin{tabular}{|c|c|c|c|c|c|c|c|}
\hline & & & $\begin{array}{l}\text { Sum of } \\
\text { Squares }\end{array}$ & $\begin{array}{l}\mathrm{D} \\
\mathrm{f}\end{array}$ & $\begin{array}{c}\text { Mean } \\
\text { Squar } \\
\text { e }\end{array}$ & $\mathrm{F}$ & Sig. \\
\hline $\begin{array}{l}\text { Hasil } \\
\text { Belajar * } \\
\text { Ergono } \\
\text { mi } \\
\text { Media } \\
\text { Ajar }\end{array}$ & $\begin{array}{l}\text { Betwee } \\
\text { n } \\
\text { Groups } \\
\text { Within G } \\
\text { Total }\end{array}$ & $\begin{array}{l}\text { (Combine } \\
\text { d) } \\
\text { Linearity } \\
\text { Deviation } \\
\text { from } \\
\text { Linearity } \\
\text { roups }\end{array}$ & $\begin{array}{r}1221,48 \\
3 \\
33,759 \\
1187,72 \\
5 \\
1743,25 \\
0 \\
2964,73 \\
3\end{array}$ & $\begin{array}{l}2 \\
6 \\
5 \\
9\end{array}$ & $\begin{array}{r}37,01 \\
5 \\
33,75 \\
9 \\
37,11 \\
6 \\
67,04 \\
8\end{array}$ & $\begin{array}{r}55 \\
2 \\
2 \\
, 50 \\
3 \\
\\
\\
, 55 \\
4\end{array}$ & $\begin{array}{r}, 94 \\
6 \\
, 48 \\
4 \\
\\
\\
, 94 \\
4\end{array}$ \\
\hline
\end{tabular}

Berdasarkan tabel 10 di atas diperoleh nilai signifikansi Deviation from Linierity adalah $0,944>0,05$. Hal ini menunjukkan bahwa ada hubungan yang linier secara signifikan antara variabel bebas dan variabel terikat.

Uji prasyarat regresi terakhir adalah uji heteroskedastisitas yang dalam penelitian ini menggunakan uji scatter plot dengan bantuan IBM SPSS Statistics dengan output sebagai berikut.

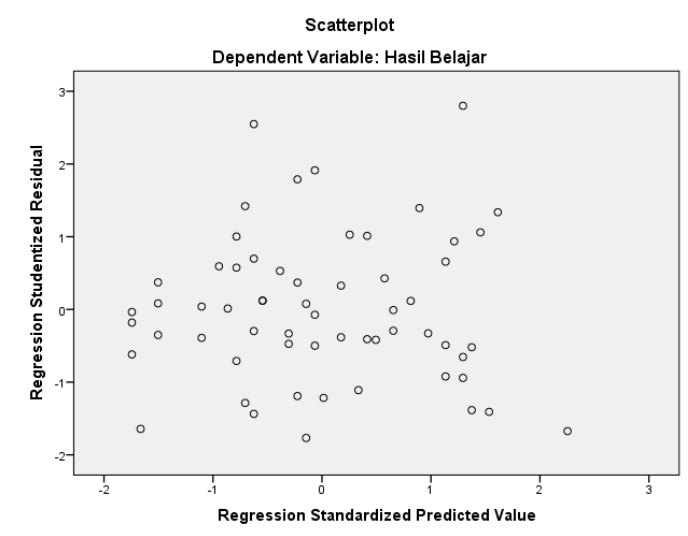

Gambar 1. Output SPSS Uji Scatterplot 
Dari hasil uji scatterplot pada gambar 1 di atas, dapat diamati bahwa gambar tidak membentuk pola tertentu seperti titiktitiknya bergelombang, menyempit kemudian melebar. Akan tetapi titik-titik pada gambar 1 tersebut menyebar di bagian atas dan bagian bawah angka 0 pada titik sumbu Y. Hal ini berarti tidak terjadi gangguan heteroskedastisitas.

Dari ketiga uji prasyarat regresi di atas, diperoleh bahwa data berdistribusi normal, terdapat hubungan yang linier secara signifikan antara variabel bebas dan variabel terikat, dan tidak terjadi gangguan heteroskedastisitas. Dengan demikian, dapat disimpulkan bahwa data pada penelitian ini memenuhi syarat untuk dilakukan uji regresi linier sederhana.

\section{Uji Hipotesis}

Setelah data memenuhi uji prasyarat, selanjutnya dilakukan uji hipotesis dimana dalam penelitian ini menggunakan uji regresi linier sederhana dengan bantuan IBM SPSS statistics. Dari Hasil output uji regresi linier sederhana, dapat dituliskan persamaan regresi linier sederhana dengan melihat hasil koefisien pada tabel berikut.

Tabel 11. Output Koefisien Regresi Linier Sederhana

Coefficients $^{\mathrm{a}}$

\begin{tabular}{|c|c|c|c|c|c|}
\hline \multirow[t]{2}{*}{ Model } & \multicolumn{2}{|c|}{$\begin{array}{c}\text { Unstandardized } \\
\text { Coefficients } \\
\end{array}$} & $\begin{array}{l}\text { Standardized } \\
\text { Coefficients }\end{array}$ & \multirow[t]{2}{*}{$\mathrm{t}$} & \multirow[t]{2}{*}{ Sig. } \\
\hline & B & $\begin{array}{l}\text { Std. } \\
\text { Error }\end{array}$ & Beta & & \\
\hline (Constant) & 68,288 & 7,736 & & 8,827 & , 000 \\
\hline $1 \begin{array}{l}\text { Ergonomi } \\
\text { Media Ajar }\end{array}$ & ,060 & 074 & 107, & 817 & 417 \\
\hline
\end{tabular}

a. Dependent Variable: Hasil Belajar

Dengan melihat nilai B pada Unstandardized Coefficients untuk konstanta dan ergonomi media ajar matematika, diperoleh persamaan regresi berikut.

$$
\mathrm{Y}=68,288+0,060 \mathrm{X} \text {. }
$$

Ini berarti bahwa dengan tanpa menggunakan media ajar yang ergonomi dalam pembelajaran di kelas, hasil belajar siswa dapat mencapai 68,288. Dengan menggunakan bantuan media ajar matematika yang ergonomis dalam pembelajaran dapat membantu siswa untuk meningkatkan hasil belajarnya sesuai dengan nilai keergonomisan dari media ajar matematika yang digunakan. Semakin baik media ajar yang digunakan, maka akan membantu siswa untuk menghasilkan skor hasil belajar yang lebih baik pula. Pernyataaan yang sama dikemukakan oleh Gatot Muhsetyo bahwa dalam menyampaikan materi matematika kepada siswa dibutuhkan media ajar yang didesain dengan baik sesuai dengan kebutuhan siswa. ${ }^{29}$ Impact yang diharapkan dengan adanya media ajar adalah minat belajar siswa meninggkat dan prestasi belajar siswa juga menjadi lebih baik. Berhubungan dengan keergonomisan, Nasr Al-Hinai, dkk. dalam penelitiannya mengatakan bahwa media belajar yang didesain dengan baik sesuai dengan analisa ergonomi dapat memberikan kenyamanan kepada siswa dan dapat menumbuhkan kepercayaan diri yang lebih baik bagi siswa di lingkungan kelas. ${ }^{30}$

Selanjutnya menguji hipotesis penelitian dengan cara membandingkan nilai thitung dengan tabel. Pada tabel $11 \mathrm{di}$ atas dapat

\footnotetext{
${ }^{29}$ Muhsetyo and Dkk.

${ }^{30} \mathrm{Nasr}$ Al-Hinai, Mahmood Al-Kindi, and Ahm Shamsuzzoha, "An Ergonomic Student Chair Design and Engineering for Classroom Environment," International Journal of Mechanical Engineering and Robotics Research 7, no. 5 (2018): 534-43, https://doi.org/10.18178/ijmerr.7.5.534-543.
} 
dilihat nilai dari thitung $=0,817$. Untuk nilai ttabel dengan taraf signifikansi 5\% dapat dilihat pada tabel $t$ dengan $\mathrm{db}=60-2=58$, sehingga nilai tabel $=0,679$. Dengan demikian $t_{\text {hitung }}=0,817>t_{\text {tabel }}=0,679$ yang berarti $\mathrm{H}_{0}$ ditolak dan $\mathrm{H}_{\mathrm{a}}$ diterima. Ini artinya bahwa terdapat pengaruh penggunaan media ajar matematika yang dianalisis secara ergonomi makro terhadap hasil belajar matematika siswa di MIN 3 Jember. Hal ini senada dengan Oktavera dalam penelitiannya yang menyatakan bahwa media ajar dalam hal ini video dan gambar memiliki pengaruh terhadap hasil belajar siswa kelas IV SD Karang Tengah 4 Tangerang. ${ }^{31}$

Selanjutnya akan dilihat signifikansi dari pengaruh media ajar matematika yang dianalisis secara ergonomi makro terhadap hasil belajar matematika siswa. Untuk melihat signifikansi dari kedua variabel dapat digunakan tabel ANOVA pada hasil output SPSS uji regresi linier berikut.

Tabel 12. Hasil Output ANOVA Uji Regresi

Linier Sederhana

ANOVA $^{\text {a }}$

\begin{tabular}{|l|r|r|r|c|c|}
\hline Model & Sum of Squares & df & Mean Square & F & Sig. \\
\hline Regression & 33,759 & 1 & 33,759 &, 668 &, $417^{\mathrm{b}}$ \\
1 Residual & 2930,975 & 58 & 50,534 & & \\
Total & 2964,733 & 59 & & & \\
\hline
\end{tabular}

a. Dependent Variable: Hasil Belajar

b. Predictors: (Constant), Ergonomi Media Ajar

Dari tabel 12 di atas nilai signifikansi adalah 0,417 >0,05. Dari hasil ini dapat kita gunakan hipotesis statistik $\mathrm{H}_{\mathrm{a}}: \mathrm{b} \neq 0$ (regresi berarti) dan $\mathrm{H}_{0}: \mathrm{b}=0$ (regresi tak berarti) dengan dasar pengambilan keputusan jika nilai Sig. > 0,05, maka $\mathrm{H}_{0}$ diterima dan $\mathrm{Ha}_{a}$

\footnotetext{
${ }^{31}$ Siska Oktavera, "Pengaruh Media Pembelajaran Dan Kemandirian Belajar Terhadap Hasil Belajar IPA Siswa Kelas IV Sekolah Dasar," Jurnal Pendidikan Dasar 6, no. 2 (2015): 327-38.
}

ditolak; dan jika nilai Sig. $<0,05$, maka $\mathrm{H}_{0}$ ditolak dan $\mathrm{H}_{a}$ diterima. ${ }^{32}$

Dengan demikian, karena nilai Sig. = 0,417 > 0,05 maka $\mathrm{H}_{0}$ diterima dan $\mathrm{H}_{\mathrm{a}}$ ditolak yang berarti bahwa regresi ini tak berarti karena $b=0$. Hal ini sesuai dengan persamaan regresi yang diperoleh di atas, yaitu $\mathrm{Y}=68,288+0,060 \mathrm{X}$. Ini artinya bahwa pengaruh media ajar matematika yang dianalisis dengan ergonomi makro tidak begitu berarti. Atau dengan kata lain, media ajar matematika tidak berpengaruh besar terhadap hasil belajar siswa. Hal ini sesuai dengan hasil penelitian yang dilakukan oleh Nurcahyo yang menyatakan bahwa media pembelajaran memberikan pengaruh kecil terhadap hasil belajar siswa pada mata pelajaran kelistrikan mesin dan konversi energi. ${ }^{33}$

\section{PENUTUP}

\section{Simpulan}

Berdasarkan paparan hasil dan pembahasan dalam penelitian ini dapat disimpulkan bahwa: 1) Persentase madia ajar matematika berdasarkan analisis ergonomi dengan pendekatan SHIP terdiri dari 1,67\% berada pada kategori sangat tinggi, 36,67\% berada pada kategori tinggi, 50\% berada pada kategori sedang, dan 11,66\% berada pada kategori rendah. Dari paparan tersebut, dapat disimpulkan bahwa media ajar yang digunakan guru memiliki kategori yang bervariasi dalam hal keergonomisannya.

\footnotetext{
32 Heumann and Shalabh, Introduction to Statistics and Data Analysis: With Exercises, Solutions and Applications in $R$.

33 Prasetyo Adhi Nurcahyo, "Pengaruh Media Pembelajaran Aplikasi Android Terhadap Hasil Belajar Siswa Kelistrikan Mesin Dan Konversi Energi," Jurnal Pendidikan Vokasional Teknik Mesin 4, no. 5 (2016): 33744.
} 
Sedangkan persentase hasil belajar siswa dengan kategori sangat tinggi sebesar $33,33 \%$, dan $66,67 \%$ berada pada kategori tinggi. Dari paparan tersebut, dapat disimpulkan bahwa rata-rata siswa memiliki kemampuan matematika tinggi; 2) Terdapat pengaruh penggunaan media ajar yang dianalisis secara ergonomi makro terhadap hasil belajar siswa di MIN 3 Jember, namun pengaruhnya tidak signifikan. Hal tersebut sesuai dengan persamaan regresi yang diperoleh yaitu, $Y=68,288+0,060 \mathrm{X}$. Regresi ini termasuk regresi yang tak berarti. Ini artinya bahwa pengaruh media ajar matematika yang dianalisis dengan ergonomi makro tidak begitu berarti. Atau dengan kata lain, media ajar matematika tidak berpengaruh besar terhadap hasil belajar siswa. Terdapat faktor lain yang dapat mempengaruhi hasil belajar matematika siswa.

\section{Saran}

Penelitian ini hanya terbatas pada hasil pengisian oleh siswa terhadap angket media ajar berdasarkan analisis ergonomi makro dan dianalisis dengan menggunakan uji statistik. Untuk memperluas kajian berikutnya, perlu diteliti lebih dalam lagi tentang analisis ergonomi makro dengan pendekatan SHIP terhadap media ajar matematika yang dianalisis dengan menggunakan pendekatan kualitatif.

\section{E. DAFTAR PUSTAKA}

Al-Hinai, Nasr, Mahmood Al-Kindi, and Ahm Shamsuzzoha. "An Ergonomic Student Chair Design and Engineering for Classroom Environment." International Journal of Mechanical Engineering and Robotics Research 7, no. 5 (2018): 53443.

https://doi.org/10.18178/ijmerr.7.5.53
4-543.

Aljandali, Abdulkader. Quantitative Analysis and IBM SPSS Statistics : A Guide for Business and Finance. Switzerland: Springer International Publishing, 2016. https://doi.org/10.1007/978-3-31945528-0.

Arifin, Zainal. Penelitian Pendidikan Metode Dan Paradigma Baru. Bandung: PT. Remaja Rosdakarya, 2012.

Arikunto, Suharsimi. Prosedur Penelitian: Suatu Pendekatan Praktik. Jakarta: Rineka Cipta, 2013.

Azwar, Saifuddin. Penyusunan Skala Psikologi. Jogjakarta: Pustaka Pelajar, 2018.

Creswell, John W., and J. David Creswell. Research Design: Qualitative, Quantitative, and Mixed Methods Approaches. Fitth Edit. United States of America: SAGE Publications, Inc, 2018.

H.W.Hendrick, and B.M.Kleiner.

Macroergonomics Theory, Methods, and Applications. New Jersey - London: Lawrence Erlbaum Associates, 2012.

Heumann, Christian, and Michael Schomaker Shalabh. Introduction to Statistics and Data Analysis: With Exercises, Solutions and Applications in R. Technometrics. Switzerland: Springer International Publishing, 2016. https://doi.org/10.1007/978-3-31946162-5.

Kholil, M. “Students' Creative Thinking Skills in Solving Mathematical Logic Problem with Open-Ended Approaches." In Journal of Physics: Conference Series, Vol. 1465, 2020.

https://doi.org/10.1088/17426596/1465/1/012044.

Kholil, Mohammad. "Implementasi Pembelajaran Inquiry Untuk Meningkatkan Kemampuan Berpikir Logis Pada Pokok Bahasan Logika Matematika." LAPLACE: Jurnal Pendidikan Matematika 1, no. 1 (2018): 15-25.

Leavy, Particia. Research Design: Quantitative, 
Qualitative, Mixed Methods, Arts-Based, and Community-Based Participatory Research Approaches. New York: The Guilford Press, 2017.

Muhsetyo, Gatot, and Dkk. Pembelajaran Matematika SD. Tangerang Selatan: Universitas Terbuka, 2013.

Nugroho, H. "Pengaruh Pembelajaran Dengan Pendekatan Ergonomi Partisipatori (Pep) Berbasis Asesmen Portofolio Terhadap Kelelahan Dan Hasil Belajar Ipa (Biologi) Siswa Kelas X Sma Tahun Pelajaran 2011/2012." Jurnal Bakti Saraswati 3, no. 02 (2014): 53-69.

Nurcahyo, Prasetyo Adhi. "Pengaruh Media Pembelajaran Aplikasi Android Terhadap Hasil Belajar Siswa Kelistrikan Mesin Dan Konversi Energi." Jurnal Pendidikan Vokasional Teknik Mesin 4, no. 5 (2016): 337-44.

Oktavera, Siska. "Pengaruh Media Pembelajaran Dan Kemandirian Belajar Terhadap Hasil Belajar IPA Siswa Kelas IV Sekolah Dasar." Jurnal Pendidikan Dasar 6, no. 2 (2015): 327-38.

Purnomo, Hari, and Kesuma Ferdianto. "Desain Sistem Kerja Pada Pengrajin Mendong Dengan Pendekatan Ergonomi Makro." Prosiding Seminar Nasional Sains Dan Teknologi Ke-2 Tahun 2011 Fakultas Teknik Universitas Wahid Hasyim Semarang, 2011, 12-17.

Soares, Marcelo M., and Francisco Rebelo. Ergonomics In Design: Methods \& Techniques. London \& New York: CRC Press, 2017.

Stockemer, Daniel. Quantitative Methods for the Social Sciences: A Practical Introduction with Examples in SPSS and Stata. Switzerland: Springer International Publishing, 2019. https://doi.org/10.1007/978-3-31999118-4.

Sugiyono. Metode Penelitian Pendidikan (Pendekatan Kuantitatif, Kualitatif Dan $R \& D)$. Bandung: Penerbit CV. Alfabeta, 2017.
Wagner, William E. Using IBM SPSS Statistics for Research Methods and Social Science Statistics. Fifth Edit. United States of America: SAGE Publications, Inc, 2015. 
118 | ibriez | Junal Kependidikan Dasar | Vol 5 No 1 Tahun 2020 